2. MakkerJ, BalarB, Niazi M, DanielM.2015Strongyloidiasis: a case with acute pancreatitis and a literature review. World J Gastroenterol. 2015;21:3367-75.

3. Adetiloye VA. A case of fatal gastrointestinal strongyloidiasis in an otherwise healthy Nigerian, masquerading as gastric outlet obstruction. Trop Geogr Med. 1992;44:60-2.

4. Appasani S, Kochhar S, Nagi B, Gupta V, Kochhar R. 2011. Benign gastric outlet obstruction-spectrum and management. Trop Gastroenterol. 2011;32:259-66.

5. Maharshi S, Puri AS, Sachdeva S, Kumar A, Dalal A, Gupta M. Aetiological spectrum of benign gastric outlet obstruction in India: new trends. Trop Doct. 2016;46,4:18691.

\section{Asymptomatic Expulsion of Self-Expanding Metal Stent Inserted for Drainage of Walled- Off Pancreatic Necrosis}

The advantages of endoscopic drainage of peripancreatic fluid or necrotic collection include lower rates of morbidity, lack of nidus for infection, and a lower incidence of percutaneous fistula formation. ${ }^{1,2}$ Conventional plastic stents placed for drainage may need frequent revisions, and these have a higher chance of obstruction and dislodgement. Hence, fully covered metal stents are now preferred, especially for the management of walled-off necrosis (WON) by cystogastrostomy or cystoenterostomy. Stent migration has very rarely been reported with covered lumen-opposing self-expandable metal stents (CSEMS). ${ }^{3,4}$

We report the spontaneous, symptom-free expulsion of such a stent from a patient in whom cystogastrostomy was done for WON.

\section{Case Report}

A 24-year-old man presented with acute abdominal pain and was diagnosed to have moderately severe acute pancreatitis (revised Atlanta classification). ${ }^{5}$ An initial $\mathrm{CT}$ of the abdomen showed features of acute necrotizing pancreatitis (CT severity index 9). In the fourth week, the patient had persistent fever and leucocytosis. Repeat CT showed a $10.9 \mathrm{~cm} \times 6.6 \mathrm{~cm} \times 7.8 \mathrm{~cm}$ WON. ERCP revealed a pancreatic duct leak, which was managed by duct stenting. The WON was treated by endoscopic cystogastrostomy using a $20 \mathrm{~mm}$ x $16 \mathrm{~mm}$ CSEMS (Nagi Stent, Taewoong Medical Co. Ltd., Gyeonggi-do, Korea) (Figure 1). Following the procedure, the patient was relieved of fever and pain. One week later, he complained of acute-onset severe abdominal pain. Free air was seen in the peritoneum on a plain radiograph but no leak of oral contrast was found on CT scan. He was managed conservatively.

Two months later, the patient developed a second episode of pancreatitis. Repeat CT imaging revealed no residual collection and the PD stent was in situ; however, the Nagi stent was missing (Figure 2). This was confirmed by endoscopy and fluoroscopy (Figure 3). The patient is doing well one year later.

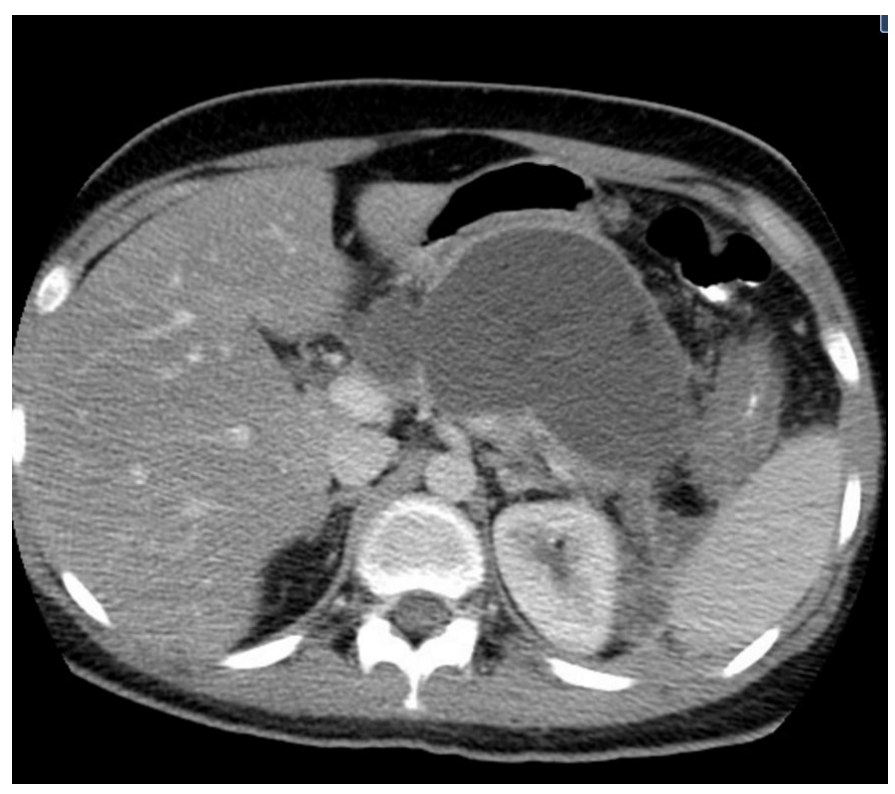

Figure 1: CT showing walled-off necrosis. 

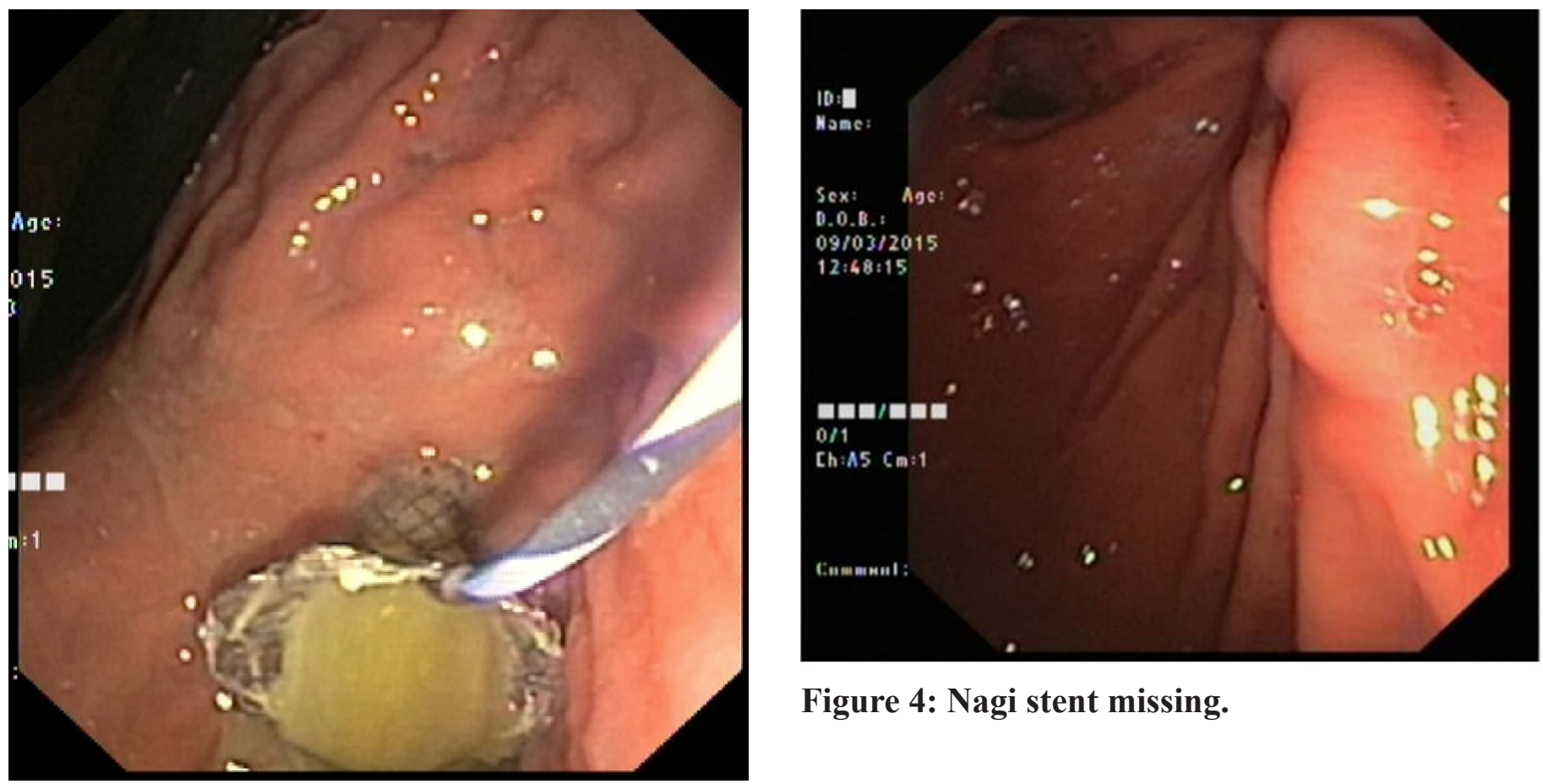

Figure 4: Nagi stent missing.

Figure 2: Nagi stent within the cystogastrostomy, with pus discharge.
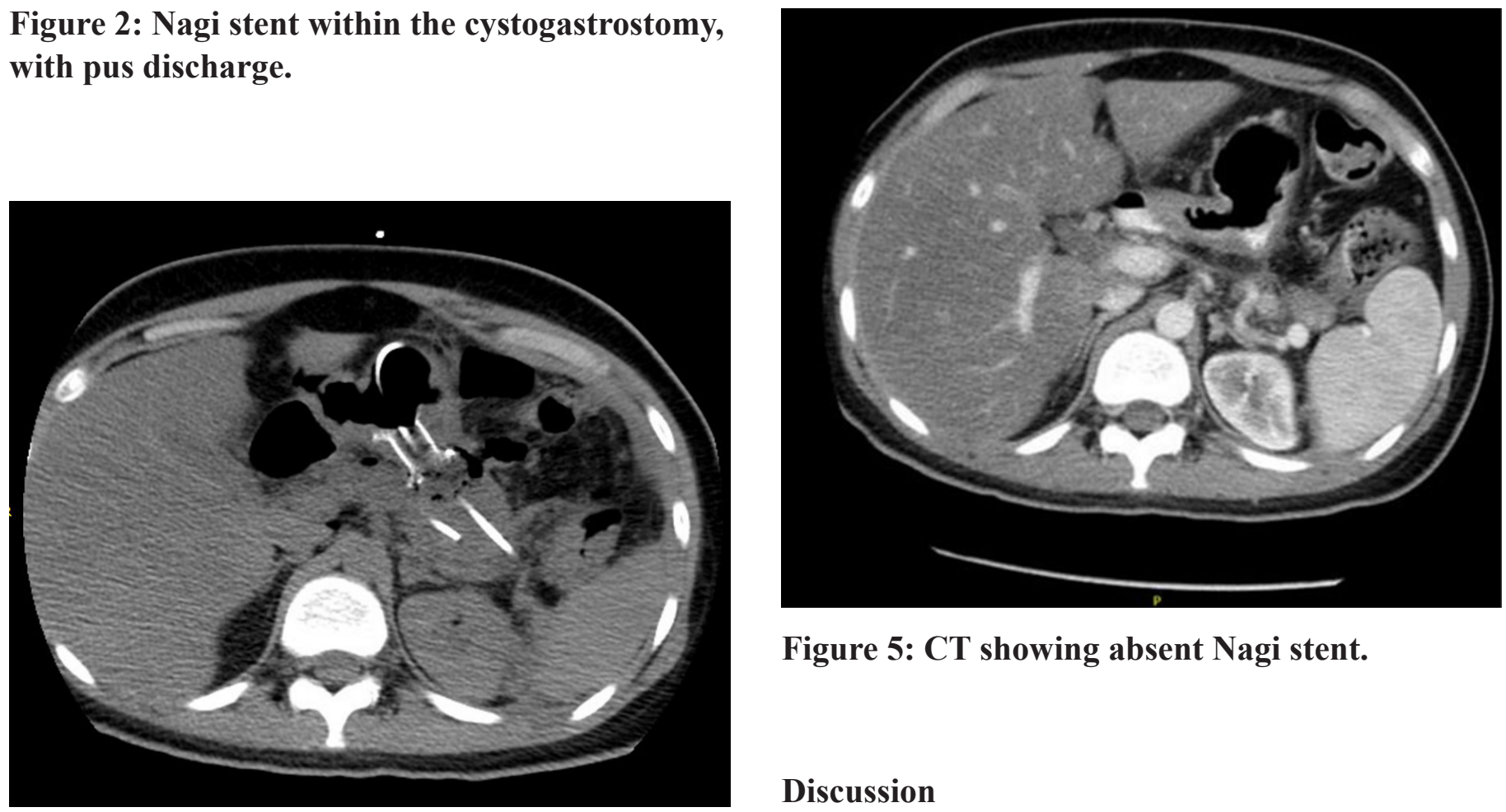

Figure 5: CT showing absent Nagi stent.

\section{Discussion}

Figure 3: CT showing Nagi stent and nasocystic tube draining the collection.

Options for treatment of pancreatic fluid or necrotic collections include surgical, percutaneous and endoscopic drainage. Pseudocysts and WON are best managed by endoscopic drainage. Advantages of the lumenopposing CSEMS over plastic stents, when used for such drainage, include less chance of obstruction, leakage or 
displacement. They can also be used as a conduit for subsequent endoscopic drainage. ${ }^{6}$

Stent displacement has been reported only rarely with these stents due to the flanges incorporated into their design. Yamamoto et al reported one patient with spontaneous stent migration among 9 patients undergoing cystogastrostomy. ${ }^{3}$ Talreja et al reported one such case in a series of 18 patients. ${ }^{4}$ In our patient, the CSEMS got spontaneously expelled through the gut without causing any symptoms and this was only incidentally detected during follow-up.

Migration of metal stents may lead to complications such as intestinal obstruction or perforation, which fortunately did not happen in our patient.

AJINKYA SONAMBEKAR DEVENDRA DESAI PHILIP ABRAHAM ANAND JOSHI TARUN GUPTA HARSHAD JOSHI RISHIKESH KALERIA VATSAL MEHTA

Department of Gastroenterology, Mumbai, India

Corresponding Author: Dr Devendra Desai Email:dr_ddesai@hindujahospital.com

\section{References}

1. Boerma D, van Gulik TM, Obertop H, et al. Internal drainage of infected pancreatic pseudocysts: safe or sorry? Dig Surg 1999;16:501-506.

2. Neff R. Pancreatic pseudocyst and fluid collections: percutaneous approaches. Surg Clin North Am 2001;81:399-403.

3. Yamamoto N, Isayama H, Kawakami H, et al. Preliminary report on a new, fully covered, metal stent designed for the treatment of pancreatic fluid collections. Gastrointest Endosc 2013;77:809.

4. Talreja JP, Shami VM, Jennifer Ku, et al. Transenteric drainage of pancreatic-fluid collections with fully covered self-expanding metallic stents. FASGE Gastroint Endosc 2008;68:1199.
5. Banks PA, Bollen TL, Dervenis C, et al. Classification of acute pancreatitis: 2012 revision of the Atlanta classification and definitions by international consensus. Gut 2013;62:102-111.

6. Perez-Miranda M, Mata L, Saracibar E, et al. Temporary access fistulas (TAFs) using covered self-expandable metal stents (cSEMS): a feasible tool for interventional pancreaticobiliary endoscopy. GastrointestEndosc 2007;65:AB123.

\section{Neonatal Intussusception:}

\section{A Rare But Important Cause of Bleeding Per Rectum in A Neonate}

Intussusception is one of the most common causes of intestinal obstruction in infancy and children. ${ }^{1}$ It can occur at any age but commonly seen between 6 to 18 months of age. ${ }^{1}$ Neonatal intussusception is rare and comprises 0.3 to $1.3 \%$ of all intussusceptions. ${ }^{2}$ The presentation, pathology, and management of neonatal intussusception are quite different from the usual infantile and childhood intussusception. The rarity of pathology in this age group and difficulty in appreciating the classic symptomatology of intussusception in the neonate contribute to the delay in diagnosis which increases the morbidity and mortality. We herein report a case of intussusception in a neonate presenting in his first 7 days of life with bleeding per rectum causing diagnostic confusion leading to delay in diagnosis and management.

\section{Case Report}

A full term male child born by spontaneous vaginal delivery with a birth weight of $2.3 \mathrm{~kg}$ and on breastfeeds presented on day 6 of life with a history of bleeding per rectum. He was dehydrated with poor capillary filling. On examination, he had tachycardia (heart rate-162/minute), 